\title{
AS IMPLICAÇÕES DA PAIDEIA E DA BILDUNG À FORMAÇÃO DE PROFESSORES
}

\author{
THE IMPLICATIONS OF PAIDEIA AND BILDUNG TO TEACHER TRAINING
}

\section{LAS IMPLICACIONES DE LA PAIDEIA Y LA BILDUNG EN LA FORMACIÓN DE PROFESORES}

\author{
Patrícia Fontana ${ }^{1}$; Martin Kuhn ${ }^{2}$
}

\begin{abstract}
RESUMO
O presente ensaio aborda a tradição de formação da Paideia grega e da Bildung humboldtiana e suas implicações à formação de professores. $\mathrm{O}$ entendimento de formação presente nessa tradição interroga a razão instrumental, hoje, predominante na formação de professores? Essa tradição nos permite pensar a formação de professores como identidades profissionais a serem biografadas? Será uma discussão em diálogo com autores que abordam e investigam a temática. A reflexão se estrutura em três partes: a primeira discute historicamente o conceito de formação. A segunda abordará o esvaziamento do processo de formação no contexto do sistema capitalista de predomínio de uma razão instrumental. E, por fim, a terceira pensa a formação docente em termos de construção de identidades entendidas como biografias, um possível caminho para romper com a razão instrumental na formação humana e docente.
\end{abstract}

PALAVRAS-CHAVE: Formação docente. Razão instrumental. Identidades. Biografias.

\section{ABSTRACT}

This essay addresses the tradition of formation of the Greek Paideia and the Bildung Humboldtian and its implications for teacher training. Does the understanding of formation present in this tradition question the instrumental reason, nowadays predominant in teacher training? Does this tradition allow us to think of the formation of teachers as professional identities to be biographed? It will be a discussion in dialogue with authors who approach and investigate the theme. The reflection is structured in three parts: the first discusses the concept of formation historically. The second will address the emptying of the process of formation in the context of the capitalist system of predominance of an instrumental reason. And finally, the third thinks of teacher training in terms of the construction of identities understood as biographies, a possible way to break with instrumental reason in human and teaching formation.

KEYWORDS: Teacher training. Instrumental reason. Identities. Biographies.

\footnotetext{
${ }^{1}$ Pedagoga pela Universidade Regional Integrada do Alto Uruguai e das Missões - URI, Câmpus de Frederico Westphalen. Mestranda do Programa de Pós-Graduação em Educação da Universidade Regional Integrada do Alto Uruguai e das Missões - URI - Frederico Westphalen - RS.

${ }^{2}$ Doutorado em Educação nas Ciências na Universidade Regional do Noroeste do Estado do Rio Grande do Sul - UNIJUÍ - Ijuí/RS - Brasil e Universidad Autónoma de Madrid. Pós-Doutorado em Educação nas Ciências na Universidade Regional do Noroeste do Estado do Rio Grande do Sul - UNIJUÍ. (Bolsista Capes/Prosup). Professor do Programa de Pós-Graduação em Educação da Universidade Regional Integrada do Alto Uruguai e das Missões - URI - Frederico Westphalen - RS.
} 


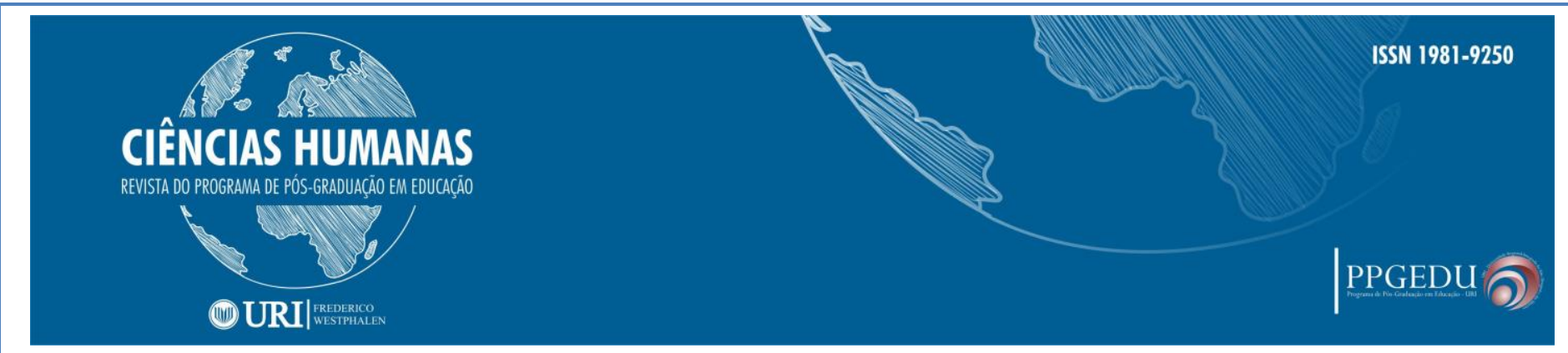

\section{RESUMEN}

El presente ensayo aborda la tradición de formación de la Paideia griega y la Bildung humboldtiana y su implicancia en la formación de profesores. ¿El concepto de formación presente en esta tradición, interroga la razón instrumental predominante en la formación de los profesores, hoy? ¿Esta tradición nos permite pensar la formación de profesores como identidades profesionales a ser biografiadas? Será una discusión en diálogo con autores que abordan e investigan esta temática. La reflexión se estructura en tres partes: la primera discute históricamente el concepto de formación. La segunda abordará el vaciamiento del proceso de formación en el contexto del sistema capitalista predominada por la razón instrumental. Y, por último, la tercera piensa la formación docente en términos de construcción de identidades entendidas como biografías, un posible camino para romper con la razón instrumental en la formación humana y docente.

PALABRAS CLAVE: Formación docente. Razón instrumental. Identidades. Biografías.

\section{CONSIDERAÇÕES INICIAIS}

Este ensaio abordará o conceito de formação ${ }^{3}$ e suas implicações à formação docente. Para pensar o conceito de formação, na compreensão de Flickinger, é válido resgatar na tradição dois modelos clássicos de formação humana que são: a Paideia, termo grego que surgiu ao longo do século V a. C. e em seu sentido profundo se vincula a formação ética; e o termo alemão Bildung ${ }^{4}$, que compreende que o ser humano se constrói como um todo e que constrói a sua autonomia e autodeterminação.

Pensar a formação humana e docente sob este prisma é entender que se trata de um processo dinâmico, inacabado, um vir a ser, inserido em um contexto histórico. No contexto capitalista, de predomínio de uma razão instrumental, como sugere Flickinger (2010), o processo de formação docente acontece de forma fragmentada e instrumentalizadora. Esse é um dos desafios a ser enfrentado para pensar a formação

${ }^{3}$ De acordo com Flickinger em A dinâmica do conceito de formação (Bildung) na atualidade.

${ }^{4}$ A palavra alemã Bildung significa, genericamente, "cultura" e pode ser considerado o duplo germânico da palavra Kultur, de origem latina. Porém, Bildung remete a vários outros registros, em virtude, antes de tudo, de seu riquíssimo campo semântico: Bild, imagem, Einbildungskraft, imaginação, Ausbildung, desenvolvimento, Bildsamkeit, flexibilidade ou plasticidade, Vorbild, modelo, Nachbild, cópia, e Urbild, arquétipo. Utilizamos Bildung para falar no grau de "formação" de um indivíduo, um povo, uma língua, uma arte: e é a partir do horizonte da arte que se determina, no mais das vezes, Bildung. Sobretudo, a palavra alemã tem uma forte conotação pedagógica e designa a formação como processo. Por exemplo, os anos de juventude de Wilhelm Meister, no romance de Goethe, são seus Lehrjahre, seus anos de aprendizado, onde ele aprende somente uma coisa, sem dúvida decisiva: aprende a formar-se (sich bilden) (SUAREZ, 2005).

\begin{tabular}{c|c|c|c}
\hline Rev. Ciências Humanas & Frederico Westphalen, RS & Pg. 19-37 & Maio/Agosto 2019 \\
\hline \multicolumn{2}{c}{ Recebido em: 09/05/2019 } & Aceito em: 03/06/2019
\end{tabular}




\section{CIÊNCIAS HUMANAS}

REVISTA DO PROGRAMA DE PÓS-GRADUAĞ̈O EM EDUCAĞ̄o

\section{(1) URI|}

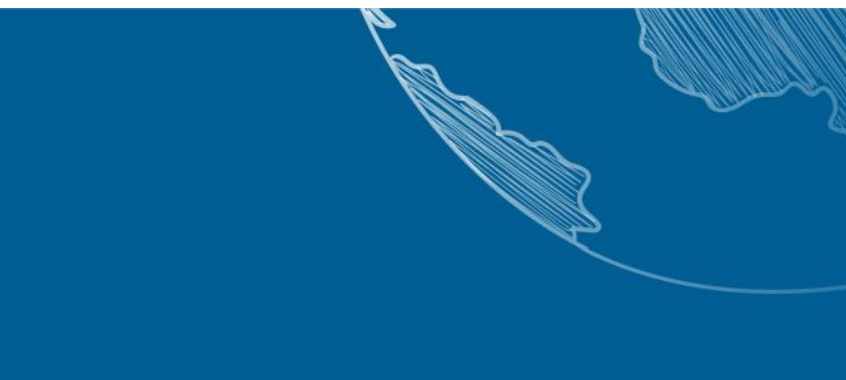

humana e docente quando interrogada em termos de identidades emancipadas e biografadas.

A problemática que desencadeou esta reflexão pode ser formulada do seguinte modo: $O$ entendimento de formação presente nessa tradição interroga a razão instrumental, hoje, predominante na formação de professores? Essa tradição nos permite pensar a formação de professores como identidades profissionais a serem biografadas? A discussão tem como objetivo compreender a formação (Paideia e Bildung) presente em nossa tradição e confrontá-la com os interesses instrumentalizadores expressos pela racionalidade neoliberal e pensar em outra perspectiva de formação de professores.

$\mathrm{O}$ texto se estrutura em três partes. A primeira objetiva compreender a tradição de formação expressa pela Paideia grega e pela Bildung humboldtiana. A segunda aborda o esvaziamento do processo de formação em um contexto de predomínio à racionalidade neoliberal, por meio de um crescente processo de instrumentalização. A terceira parte propõe a formação docente em termos de construção de identidades, compreendidas como trajetórias e biografias. Essa estrutura visa a um olhar à tradição e um olhar para o presente e pensar possibilidades para qualificar o processo de formação humana e docente ante os desafios do nosso tempo.

\section{O MODELO DE FORMAÇÃO DA PAIDEIA E DA BILDUNG}

Todo o processo de formação está sujeito a metamorfoses. Isso acontece por estar inserida em um contexto histórico, que influencia a constituição do sujeito e que o mesmo contribui para a construção desta história. De acordo com Flickinger (2010, p. 35), "no que tange à historiografia, cada um de nós faz parte desse fluxo incessante da história. Mais ainda, cada um de nós contribui, de modo mais ou menos expressivo, à determinação de seus rumos". Nesse sentido, não somos somente objetos da história, mas também sujeitos que participam de sua construção.

Significa que participamos de nosso processo de formação humana e esse processo educativo tem caráter humanizador. Savater (2008, p. 35), afirma que "para ser 


\section{CIÊNCIAS HUMANAS}

REVISTA DO PROGRAMA DE PÓS-GRADUAĞ̈O EM EDUCAĞ̄o

\section{(1) URI|}

hombre no basta con nacer, sino que hay tambíen que aprender. La genética nos predispone a llegar a ser humanos pero sólo por médio de la educación y la convivencia social conseguimos efetivamente serlo". Trata-se primeiramente de ser trazido para dentro da cultura, o que não significa negar a possível liberdade do ser humano, mas possibilitar que essa se desenvolva em plenitude, que cada sujeito possa constituir sua identidade e emancipar-se. Nesse sentido, o conceito de formação tem uma tradição e no do tempo assume diferentes tonalidades.

Para ampliar o conceito de formação é válido resgatar a tradição cultural e histórica dos termos Paideia e Bildung. De acordo com Flickinger (2010, p. 177), "o conceito de formação, hoje considerado clássico, remete a ideias vinculadas às noções de Paideia e Bildung; noções estas que fogem de uma tradução direta, em uma palavra só". Conforme o filósofo, o termo Paideia remete a tradição grega e traz "consigo uma forte conotação ética, pouco presente na concepção contemporânea da educação. Tampouco nos damos conta de que a formação, tomada como Bildung nos leva de volta às origens do pensamento iluminista" de Wilhelm von Humboldt, fins dos século XVIII e primeiras décadas do século XIX.

No ideal de formação dos gregos, a primeira expressão é Araté, que é caracterizado pela formação de atributos físicos, espirituais e morais. Nestes atributos se destacam força, coragem, habilidade. Valorizavam-se a música, a ginástica, educação física, oratória, retórica, ciência, música e filosofia. Na tradição grega, pelo século $\mathrm{V}$ a. C, se percebe que a formação da Araté é insuficiente. Então, se chega ao conceito de formação da Paideia, que incorpora a dimensão política da formação (cidadão), conferindo-lhe as condições de viver na pólis.

A Paideia objetivava formar o homem cidadão capaz de agir e se relacionar baseado na ética e na justiça. Conforme Jaeger (2001), citado por Flickinger (2010, p. 147), "a Paideia grega desde sempre reconhecera a necessária interconexão entre o conteúdo verdadeiro e a adequação ética do saber, fazendo que somente aquele saber identificado com as normas do agir ético fosse verdadeiro e vice-versa". Nesse sentido, a Paideia almeja formar o homem em seu mais alto valor. 


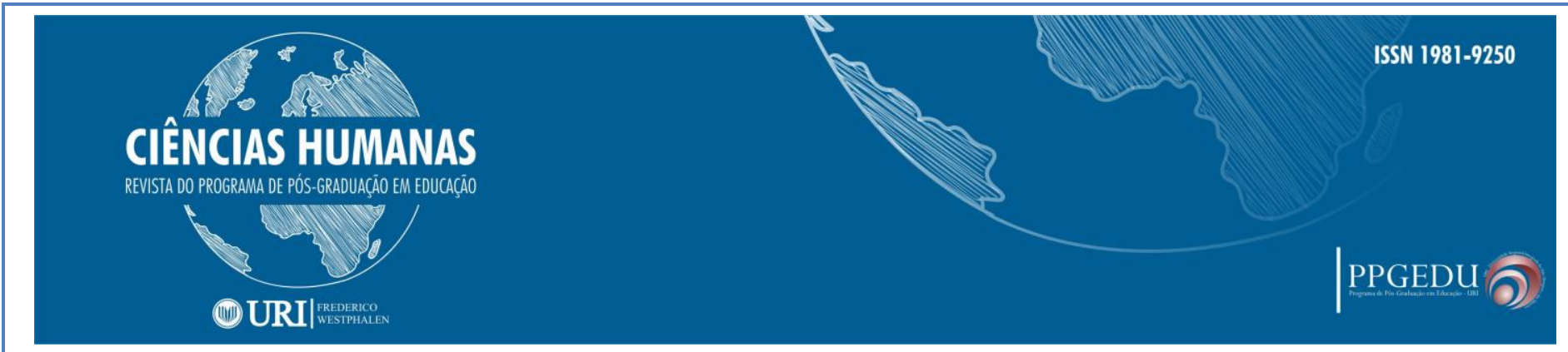

Já o modelo de formação da Bildung de Humboldt, forte no século XVIII e XIX, fortalecida pelas humanidades, assume uma perspectiva humanista. No ideal da Bildung humboldtiana, o ser humano é compreendido, conforme Flickinger (2010), com autodeterminação racional, isto é, com capacidade de se formar e de agir dotado pela razão. Agir dotado pela razão confere ao sujeito autonomia para pensar, refletir e construir sua relação com o outro e com o mundo. Conforme Flickinger (2010, p. 29) “o ser humano viu-se forçado, desse modo, a tomar seu destino nas próprias mãos, pois a autonomia da razão se tornaria a base legitimadora da construção de nossa relação com o mundo".

$\mathrm{Na}$ ótica da Bildung, o sujeito está sempre em construção, buscando compreender o mundo e a existência e adquirindo a liberdade que o humaniza e o torna capaz de fazer uso responsável da razão. Flickinger (2010, p. 177) ressalta que o objetivo do Bildung em relação ao ser humano é "a formação máxima e mais proporcional possível de suas forças no intuito de as integrar em um todo", participar do mundo comum. Assim, ao pensar a formação humana como um todo é válido evidenciar que o ser humano é um ser de cultura, de natureza aberta, isto é, capaz de se reinventar como pessoa.

Neste sentido, se percebe que o contexto em que o ser humano está inserido tem grande influência no processo de formação. Segundo Flickinger (2010, p. 43) "no diálogo vivo é a linguagem a partir da qual se abre o horizonte inesgotável e o sentido; por isso mesmo, é ela que constitui e possibilita a experiência hermenêutica". É pela linguagem que ocorre o processo de formação, é pela linguagem que nos constituímos como humanos. Pimenta (2009, p. 22) pondera que nessa perspectiva de formação, a educação, a escola e os professores têm "um grande trabalho a realizar com as crianças e os jovens, que é proceder à mediação entre a sociedade da informação e os alunos, no sentido de possibilitar-lhes pelo desenvolvimento da reflexão a sabedoria necessária à permanente construção do humano".

O processo formativo, desse modo, influencia e contribui para a constituição da identidade dos sujeitos. Em relação ao processo formativo e a constituição da identidade docente, Nóvoa (1995, p. 17), destaca que "o processo identitário passa também pela 


\section{CIÊNCIAS HUMANAS}

REVISTA DO PROGRAMA DE PÓS-GRADUAĞ̈O EM EDUCAĞ̄o

\section{(1) URI|}

capacidade de exercermos com autonomia, a nossa atividade, pelo sentimento de que controlamos o nosso trabalho". Desse modo, a maneira como cada um de nós compreende a formação humana está diretamente dependente daquilo que somos como pessoas quando exercemos o ensino e a aprendizagem. A escola, desse modo, participação da formação dessas subjetividades.

No ato de ensinar/formar os sujeitos o professor (subjetividade e profissionalidade) não são duas instâncias separadas. A este respeito Nóvoa (1995, p. 17) destaca que "aqui estamos. Nós e a profissão. E as opções que cada um de nós tem de fazer como professor, as quais cruzam a nossa maneira de ser com a nossa maneira de ensinar e desvendam na nossa maneira de ensinar a nossa maneira de ser". Conclui a sua reflexão considerando que na identidade do professor "é impossível separar o eu profissional do eu pessoal". O eu profissional e o eu pessoal são, nesse movimento, construções imbricadas. Para compreender esse processo de formação é importante considerar a sua historicidade, pois tal possibilita traduzir (ler, interpretar e compreender a tradição) o processo formativo em sua realidade concreta, com seus atributos e valores.

Reconhecer a tradição no processo de formação deve ser acolhido com abertura e, nesse sentido, o conceito de formação presente na Paideia grega, na perspectiva de um saber ético para a vida em comum, e na Bildung humboldtiana de uma autonomia da razão, é significativo, uma vez que interroga e nos permite pensar a razão instrumental que tem marcado a educação de nosso tempo. Dessa forma, essas duas tradições de formação deixaram um legado importante à educação e à formação de professores, à medida que se ocupam da tarefa de compreender a formação humana ética, de sujeitos emancipados, autônomos, autodeterminados e livres no mundo comum.

\section{ESVAZIAMENTO DA PAIDEIA E DA BILDUNG: A RAZÃO INSTRUMENTAL}

A retomada do conceito de formação da Paideia e da Bildung, ainda que de modo muito preliminar, é para nos aproximar da compreensão de formação presentes 


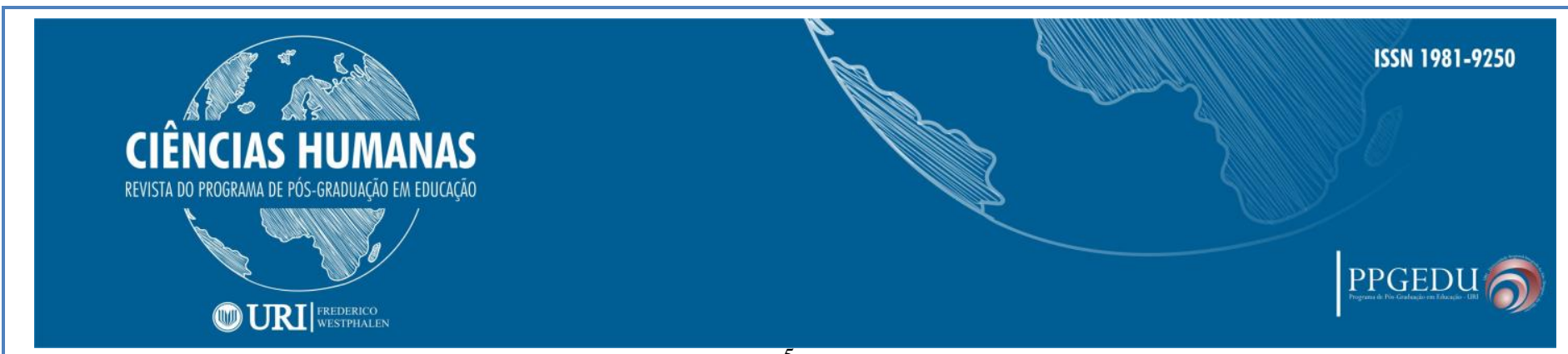

nessa tradição. Na racionalidade neoliberal ${ }^{5}$, se constata que a compreensão clássica de formação humana grega e da humanista humboldtiana se esvaziaram. Flickinger (2010, p. 178) destaca que "nem a conotação primordialmente ética da Paideia, nem a expectativa de poder conquistar sua autodeterminação por meio da Bildung moderna marcaram o nosso entendimento do conceito de formação hoje". Nesse sentido, o filósofo alerta que o "conceito parece ser cada vez mais distante de qualquer comprometimento com essas suas raízes", uma formação mais alargada do humano e que "deveríamos perguntar pelos motivos condicionadores dessas mudanças aparentemente substanciais" (Ibidem, p. 178).

Em nosso tempo o processo de formação humana assume os traços marcantes da racionalidade instrumental. Facci $(2004$, p. 15) pondera que "não há como negar que o mundo no qual vivemos tudo, absolutamente tudo, incluindo o direito à educação e ao próprio processo de humanização, no sentido de acesso aos bens culturais historicamente produzidos, esta entregue ao espírito mercantilista do capital". Assim, no âmbito das relações ordinárias do trabalho pedagógico se tornou presente a tendência que procura traduzir, sempre mais, a escola como instituição que vende o conhecimento e o conceito de professor/a como sendo alguém que vende, no mercado de trabalho, uma atividade como qualquer outro trabalhador/a. Isto é, vende-se e compra-se, cada vez mais, essa mercadoria, através de "empresas" do ramo da economia da educação. A prática da educação, muitas vezes, em primeiro plano, é vista como "negócio" e, do mesmo modo, a formação de professores virou um negócio disputado pelo mercado. Mais do que isso, o sentido do trabalho pedagógico assume caráter cada vez mais instrumental, prático e utilitário.

Esta realidade coloca em questão o processo emancipatório do sujeito, privandoo da autonomia intelectual e conformando-o com a técnica. De acordo com Horkheimer (2002 p. 7) "parece que enquanto o conhecimento técnico expande o horizonte da atividade e do pensamento humano, a autonomia do homem enquanto indivíduo, a sua

\footnotetext{
${ }^{5}$ Pierre Dardot e Christian Laval (2016, p. 16; 30) afirmam o neoliberalismo como uma racionalidade que tende a estruturar e organizar a existência humana em sua totalidade, produzindo "certos tipos de relações sociais, certas maneiras de viver subjetividades", que se estendem a todas as dimensões da existência humana como a nova razão do mundo: expandir e acumular capital.
} 


\title{
CIÊNCIAS HUMANAS
}

REVISTA DO PROGRAMA DE PÓS-GRADUAÇ̄OA EM EDUCAÇ̄̃O

\section{(1) URI|}

capacidade de opor resistência ao crescente mecanismo de manipulação de massas (...) sofreram aparentemente uma redução". Ou seja, a razão instrumental avança a passos largos sobre a racionalidade comunicativa, como diria Habermas (2001). A este respeito Facci (2004, p. 8-9) reitera que "temos assistido a um maior submetimento do indivíduo, a uma maior angústia e medo pela vida e pelo futuro, mais solidão e não o esperado triunfo da liberdade do indivíduo, conforme apregoa o neoliberalismo".

A razão instrumental destitui o pensamento reflexivo e a criticidade e incorpora pensamentos padronizados e constituídos por conhecimentos técnicos já produzidos, que respondam as supostas exigências da qualificação profissional requeridas pelo mercado. Para Horkheimer (2002 p. 26) o homem

\begin{abstract}
Tendo cedido em sua autonomia, a razão tornou-se um instrumento. (...) A razão tornou-se algo inteiramente aproveitado no processo social. Seu valor operacional, seu papel no domínio dos homens e da natureza tornou-se o único critério para avaliá-la. (...) Os conceitos foram "aerodinamizados", racionalizados, tornaram-se instrumentos de economia de mão-de-obra. É como se o próprio pensamento tivesse se reduzido ao nível do processo industrial, submetido a um programa estrito, em suma, tivesse se tornado uma parte e uma parcela da produção.
\end{abstract}

O sujeito é reduzido e manipulado, limitando suas possibilidades de interrogar a lógica instrumental predominante na sociedade. O pensar se afina com a lógica mercantil. A razão instrumental limita as possibilidades de emancipação do sujeito, pois está alinhada às intenções do capital. Esta realidade gera mudanças no modo de viver e de ser das pessoas, modifica sua cultura, uma vez que visa ao individualismo, à concorrência e à competição. Longe de proporcionar uma vida feliz, a indústria cultural, o mercado, aliena o ser humano. Em boa medida, o conforma a essa "nova razão do mundo", conforme Dardot e Laval (2016). De acordo com Adorno e Horkheimer, (1991, p. IX)

[...] a indústria cultural, ao aspirar à integração vertical de seus consumidores, não apenas adapta seus produtos ao consumo das massas, mas, em larga medida, determina o próprio consumo. Interessada nos homens apenas enquanto consumidores ou empregados, a indústria cultural reduz a humanidade, em seu conjunto, assim como cada um de seus elementos, às condições que representam seus interesses. 


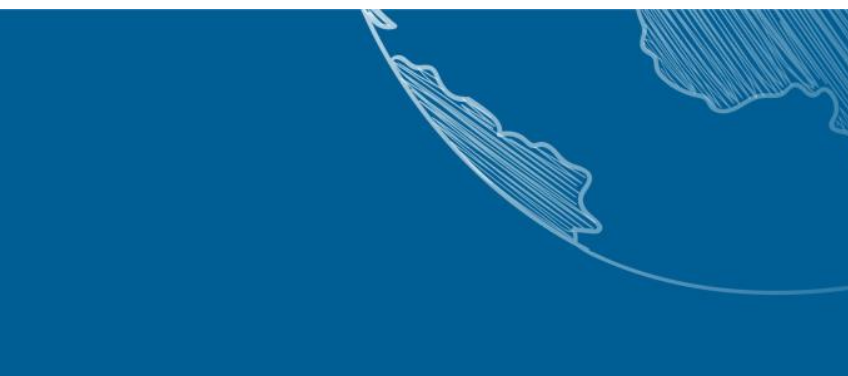

Sob este olhar, o sistema capitalista segue a dinâmica mercantil. Instaura uma nova racionalidade à condução dos negócios entre os homens e desses com a natureza. Esta dinâmica atinge o processo de formação que é pressionado a estreitar as relações entre educação/formação instrumental e mercado de trabalho. Flickinger (2010, p. 179) aponta para uma outra relação entre indivíduo e sociedade. Destaca que "a integração do indivíduo no mercado de trabalho que lhe providencia não apenas os meios materiais para sua subsistência, senão, antes de tudo, o reconhecimento como membro valioso da comunidade". É pela sua atividade produtiva, participação na vida coletiva, que este passa a ser valorizado.

A sociedade concorrencial desencadeia a competitividade em todos os setores da vida humana. Facci (2004, p. 13) destaca que "[...] as políticas neoliberais incrementaram e incrementam as a desigualdade social, racial (...), reproduzindo os privilégios da minoria que tem o poder econômico e político". Em um contexto dominando pela lógica do capital cada um é empresa de si. Ainda, conforme a autora, frente a esta realidade destaca que se "agrava o individualismo e a competição selvagem, quebrando os laços da solidariedade coletiva e intensificam o processo antidemocrático de seleção natural onde os melhores triunfam e os mais frágeis perdem”. Cada vez mais um lugar ao sol se torna uma disputa em que o outro é meu inimigo, meu concorrente.

Essa razão instrumental e utilitarista, para além de explorar à exaustão a natureza como mercadoria, compreende igualmente o próprio ser humano como mercadoria. A educação e a formação têm por tarefa preparar de modo útil essa mercadoria. $\mathrm{O}$ caráter instrumentalizador assumido pelo processo de formação no contexto neoliberal, fragmenta o sujeito até perder a sua condição humana, produzem-se subjetividades sujeitadas e identificadas cada vez mais ao caráter inanimado, quantitativo e automático dos objetos ou mercadorias circulantes no mercado.

Pondera Flickinger (2010, p. XIX) que nesse movimento de instrumentalização do ser humano ocorre "no contexto de uma pedagogia orientada nos princípios da objetividade e instrumentalidade pós-cartesiana" e que tal compreensão traz consigo o "risco da desvirtuação da pedagogia de seu sentido originário que é a formação e 


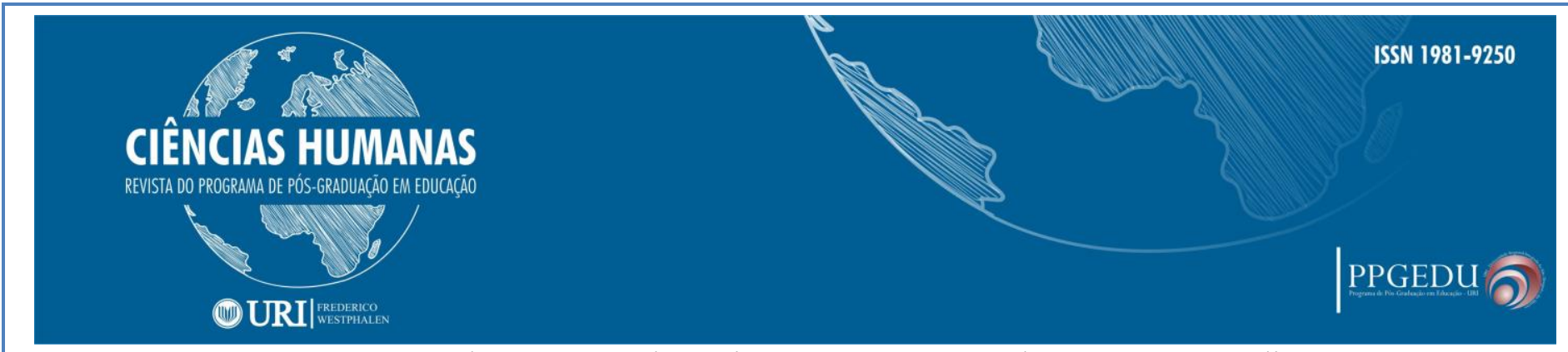

humanização do ser humano". Tal movimento tem se tornado crescente nos discursos e nas práticas pedagógicas educativas. No âmbito da formação de professores, isso se torna presente quando prepondera uma demanda instrumentalizadora, técnica, nos cursos de formação inicial e continuada.

A razão instrumental segue os padrões da utilidade e da produtividade. Isto é, espera que o sujeito aprenda a técnica, os procedimentos, o que lhe é útil para competir e conseguir espaço no mercado, caso isto não aconteça, é excluído. Flickinger (2010, p. 179) salienta que:

Quem quiser alcançar um mínimo de independência pessoal terá de concentrar todo o esforço no aperfeiçoamento das condições que o acesso do mercado exige. Ao mesmo tempo sabemos que a visão do trabalho, vigente na economia capitalista, se baseia em um modelo social não orientado pelas necessidades do homem, senão pelas exigências do mercado financeiro, isto é, do capital.

Nesse cenário se percebe que não há muito espaço para uma proposta de formação humana em sintonia com a Paideia e a Bildung. Nesse movimento o ser humano é visto como capital humano e a formação assume um caráter pragmático, que prepara o sujeito para o mundo produtivo, isto é, aprender a "fazer" para produzir. Tal entendimento é reiterado por Dardot e Laval (2016, p. 17) quando afirmam que uma nova racionalidade orienta o mundo. Para eles a "racionalidade neoliberal ${ }^{6}$ tem como característica principal a generalização da concorrência como norma de conduta e da empresa como modelo de subjetivação". Se em muitos momentos nos referimos ao neoliberalismo como presente na organização dos elementos conjunturais e estruturais (discurso), mas é na concretude da vida (práticas sociais) que ele se traduz (relações capital/trabalho, no consumo, na saúde, na educação, nos direitos sociais, etc.).

A produção de subjetividades neoliberais requer, no entender dos autores, "uma política de educação de massas que prepare os homens para as funções econômicas especializadas que os aguardam e para o espírito do capitalismo a que devem aderir para

\footnotetext{
${ }^{6}$ Por racionalidade noeliberal os autores entendem "um sistema de normas que hoje estão profundamente inscritas nas práticas governamentais, nas políticas institucionais, nos estilos gerenciais". Mais do que isso, excede "em muito a esfera mercantil e financeira em que reina o capital" e se estende "muito além das fronteiras estritas do mercado, em especial produzindo uma subjetividade "contábil" pela criação de concorrência sistemática entre os indivíduos" (DARDOT; LAVAL, 2016, p. 30).
}

\begin{tabular}{c|c|c|c}
\hline Rev. Ciências Humanas & Frederico Westphalen, RS & Pg. 19-37 & Maio/Agosto 2019 \\
\hline \multicolumn{2}{c}{ Recebido em: 09/05/2019 } & Aceito em: 03/06/2019 \\
\hline
\end{tabular}




\section{CIÊNCIAS HUMANAS}

REVISTA DO PROGRAMA DE PÓS-GRADUAĞ̈O EM EDUCAĞ̄o

\section{(1) URI|}

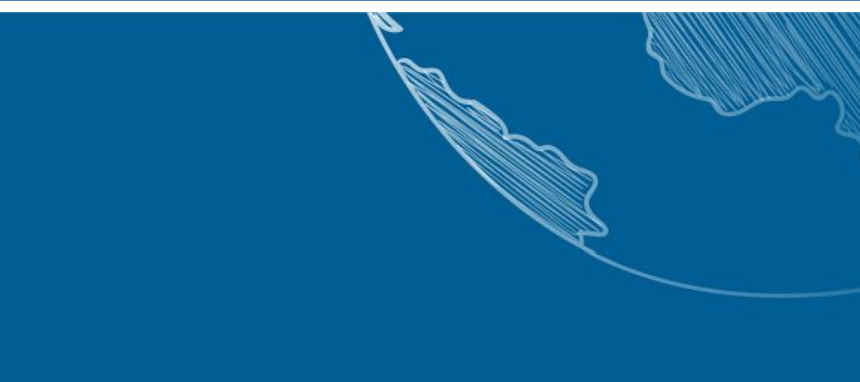

viver "em paz uma Grande Sociedade de membros interdependentes"” (DARDOT; LAVAL, 2016, p. 92). Trata-se de produzir capital humano para esse mundo intensamente concorrencial e competitivo. Os estudantes ou futuros professores, "como futuros trabalhadores - devem obter as indispensáveis habilidades e disposições para competir eficientemente e efetivamente" (APPLE, 2011, p. 96), nesse mercado competitivo e concorrencial. Nesse sentido, pondera Charlot (2013, p.44) "Vai-se à escola para aumentar a quantidade e a qualidade do seu 'capital humano', entrar logo naquela concorrência que é a lei fundamental do universo e, mais tarde, ocupar o melhor lugar possível no mercado do trabalho". Essa é a racionalidade técnica ${ }^{7}$, eficiência econômica e administrativa, dirigida à educação.

Flickinger (2010, p. 180) acrescenta que essa nova "sociedade de trabalho efetua-se por meio da economização abrangente do homem, desacoplando-se assim do que originalmente compôs o ideal da formação no seu pleno sentido da Bildung; a saber, do interesse ético-social e bibliográfico-construtivo". A produção de subjetividades neoliberais requer, no entender dos autores "uma política de educação de massas que prepare os homens para as funções econômicas especializadas que os aguardam e para o espírito do capitalismo a que devem aderir para viver 'em paz uma Grande Sociedade de membros interdependentes"” (DARDOT; LAVAL, 2016, p. 92). Trata-se de produzir capital humano para esse mundo intensamente concorrencial e competitivo. Os estudantes, "como futuros trabalhadores - devem obter as indispensáveis habilidades e disposições para competir eficientemente e efetivamente" (APPLE, 2011, p. 96).

O contexto descrito impacta diretamente na educação e, principalmente, na formação docente, pois expõe o processo formativo ao risco de seguir um padrão préformatado de caráter instrumental. A este propósito Flickinger (2010, p.135) ressalta que "uma formação em que prevalecessem definições de antemão prontas e em relação

\footnotetext{
${ }^{7}$ Racionalidade técnica ou a Zweckrationalität é "o tipo de racionalidade que se revela na escolha dos meios mais adequados para realizar fins predeterminados. Estabelece-se uma conexão íntima entre racionalidade e eficiência empírica, ou seja, entre racionalidade e os meios técnicos adequados para atingir determinados fins" (GOERGEN, 2005, p. 20).
} 


\section{CIÊNCIAS HUMANAS}

REVISTA DO PROGRAMA DE PÓS-GRADUAĞ̈O EM EDUCAĞ̄o

\section{(1) URI|}

às quais não se pudesse rebelar seria a própria negação do sentido propriamente dito pedagógico do "currículo", avesso, como o termo já diz, a toda determinação petrificadora". Isso revela que uma formação pré-formatada nega o sentido pedagógico da Paideia e da Bildung de formar sujeitos capazes de interrogar e de participar de modo ético, autônomo e responsável da sociedade. Por fim, destaca o filósofo que nesse movimento, "o processo de formação vê-se guiado pelas diretrizes da racionalidade econômica que servem também de critérios para a avaliação dos resultados" (Idem, p. 180). Parece-nos assim, que em um contexto de crescente predomínio de uma razão técnico-instrumental, mais se torna exigente questionar os sentidos impressos em nossas práticas educativas e nos processos de formação de professores.

\section{FORMAÇÃO DOCENTE: IDENTIDADES, TRAJETÓRIAS E OU BIOGRAFIAS}

A realidade acima exposta produz implicações ao sistema educacional e à formação docente. Uma alternativa para o sistema educacional à referida realidade é pensar a formação docente em termos de identidades, trajetórias e/ou biografias. É um movimento de resistência. Assim, é importante no itinerário formativo oportunizar ao sujeito a possibilidade de constituir sua identidade e autobiografar-se em âmbito pessoal e profissional. Esta dinâmica proporcionará a formação de docentes emancipados, esclarecidos, capazes interrogar e pensar às práticas pedagógicas e à docência. Sacristán (1995, p. 74) destaca que "o professor não é um técnico nem um improvisador, mas sim um profissional que pode utilizar o seu conhecimento e a sua experiência para se desenvolver em contextos pedagógicos práticos e preexistentes”. Significa compreender a formação de professores para além do domínio de procedimentos técnicos e instrumentais, ela deve assumir um compromisso ético, emancipador.

A este propósito, Libâneo (2013, p. 31), destaca que o valor da aprendizagem está em "transformar-se num sujeito pensante, de modo que aprenda a utilizar seu potencial de pensamento por meio de meios cognitivos de construção e reconstrução de conceitos, habilidades, atitudes, valores". Certamente, este caminho deixará uma marca indelével na vida dos estudantes e futuros professores, pois terão condições de protagonizarem com responsabilidade social sua cidadania e sua docência. 


\section{CIÊNCIAS HUMANAS}

REVISTA DO PROGRAMA DE PÓS-GRADUAĞ̈O EM EDUCAĞ̄o

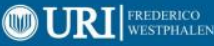

Fundamentalmente para Libâneo (2013, p. 37) a tarefa de formação docente é complexa e exige que se os prepare para o pensar. "A tarefa de ensinar a pensar requer dos professores o conhecimento de estratégias de ensino e de desenvolvimento de suas próprias competências do pensar". O ato de ensinar os alunos revela a capacidade que o professor tem de pensar e construir o próprio conhecimento. Se um professor não dispõe das "habilidades de pensamento, se não sabe "aprender a aprender", se é incapaz de organizar e regular suas próprias atividades de aprendizagem, será impossível ajudar os alunos a potencializarem suas capacidades cognitivas" (LIBÂNEO, 2013, p. 37). Afinal, que identidades profissionais são as construídas, hoje, nos processos formativos de docentes?

A construção da identidade toca a vida do sujeito como um todo, isto é, integra o contexto cultural, a subjetividade, o contexto sócio-político, o cenário econômico, etc. No caso da profissionalidade do professor, Facci (2004, p. 61), afirma que "a identidade não é só um conceito, mas sim uma construção sociocoletiva na qual a subjetividade se relaciona com a própria profissão". Nela se incorporam as duas dimensões da vida humana que são: a dimensão individual, que tem como centro a personalidade da pessoa, a subjetividade e as experiências de vida e a dimensão coletiva, que engloba a relação com o contexto social e com o outro.

A este propósito Dubar (1997, p. 110) ressalta que "não se faz a identidade das pessoas sem elas e, contudo, não se pode dispensar os outros para forjar sua própria identidade". Assim, o processo de socialização/humanização é pressuposto para a constituição das identidades, tanto as individuais quanto as profissionais. É no diálogo/confronto com o outro, com o constituído, com a tradição, com as vivências, com os novos desafios que os cenários nos apresentam que se constituem as identidades. Também, é nesse cenário que é possível compreendê-la.

É válido ressaltar que na construção identitária se busca um estilo de vida que vai além de um mero repetir, reproduzir, pois se constrói o modo de ser, o caráter, os valores e, no caso da identidade profissional do professor, as referências pedagógicas, epistemológicas, as concepções de educação, as práticas requeridas pela profissão, referências que irão fundamentar a vida e a ação profissional. Este processo é dinâmico, 


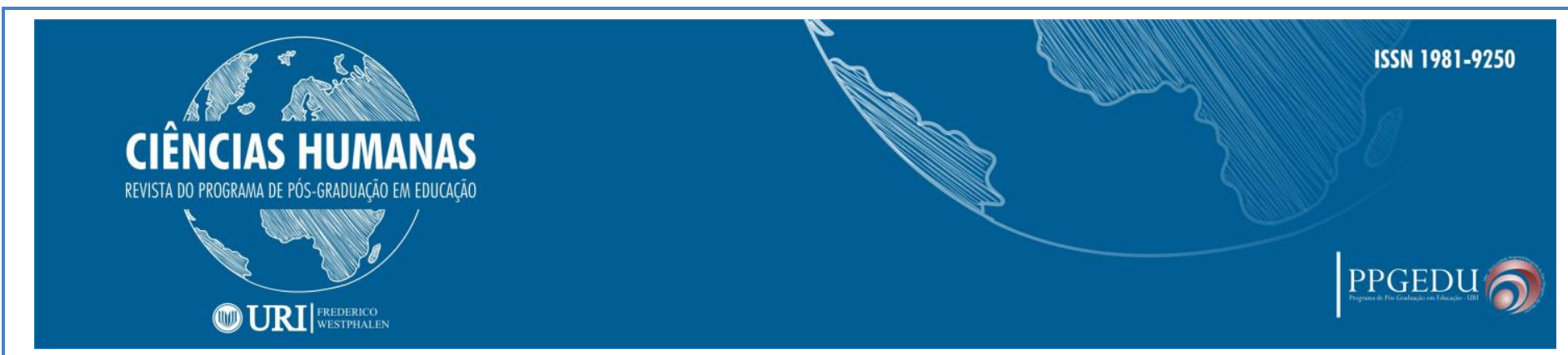

sujeito a mudanças e transformações, pois é histórico. Stein (1993, p. 41) destaca que "a nossa identidade não é a identidade de um saco de batatas ou de um balde de água num lugar determinado". Ou seja, ela não é fixa nem estática, é marcada pelas configurações espaço-temporais. Nesse sentido, o filósofo acrescenta que pelo fato de estarmos em um lugar "já o transformamos, já buscamos relações, e isto desde o primeiro momento de nossa experiência. Portanto, a identidade não é uma pura identidade no espaço e no tempo".

Pensar a formação inicial e continuada de professores a partir da afirmação de Stein é compreender que o professor ao longo do itinerário formativo vai construindo sua identidade, se apropriando de conhecimentos, habilidades, saberes, pressupostos éticos, morais e políticos para o exercício da profissão. Nesse sentido, a identidade do professor não é independente da história pessoal, das experiências familiares, do contexto social, cultural, político, econômico, religioso, etc.. Facci (2004, p. 61) destaca que "a identidade do professor está relacionada com a própria identidade da profissão docente, com a revisão constante dos significados sociais da profissão docente e com o sentido que tem para cada membro dessa classe profissional o "ser professor". A identidade do professor é produzida. Sendo construída, podemos interrogar que referências a tem balizado em nosso tempo.

No processo de formação inicial é importante acolher e considerar todas as experiências prévias vivenciadas pelos futuros docentes. A socialização primária, que acontece no seio da família, as vivências da escolarização, bem como as pré-concepções sobre o ser professor que foram se constituindo em sua trajetória escolar, participam da configuração de sua identidade, o que pode impor dificuldades de romper com determinadas marcas. Pimenta (2009, p. 19) afirma que "uma identidade profissional se constrói, pois, a partir da significação social da profissão; da revisão constante dos significados sociais da profissão; da revisão das tradições”.

Nesta perspectiva se confirma que a identidade é construção biográfica. Ela é produzida no encontro dialógico com a tradição, com seus significados, com seus conhecimentos, com suas práticas, mas também, com os desafios dos contextos em que se exerce a profissão. É desse encontro que emerge a história pessoal e profissional que 


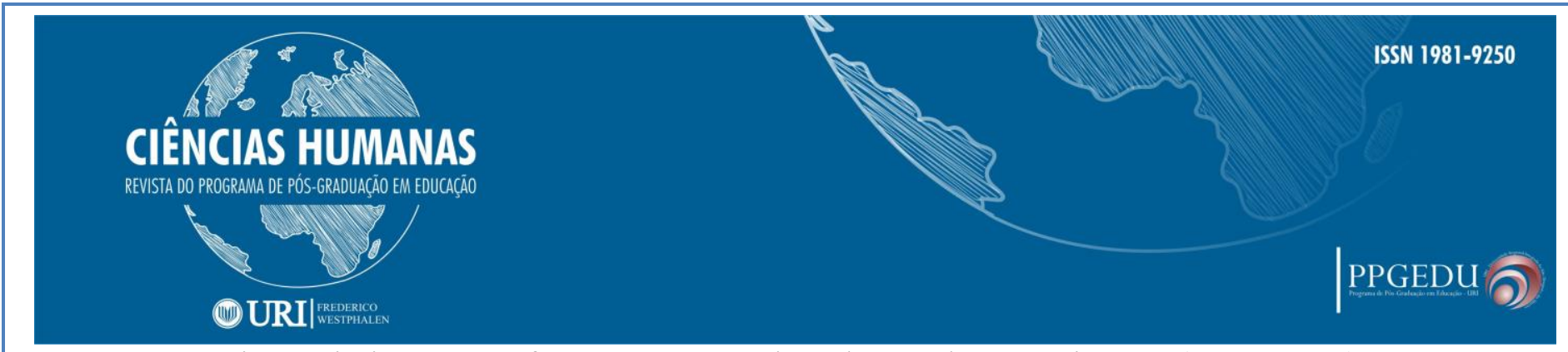

o vai constituir o ser professor. Desse modo e de acordo com Pimenta (2009, p. 18), “a identidade não é um dado imutável. Nem externo, que possa ser adquirido. Mas é um processo de construção do sujeito historicamente situado". Reafirma-se que nesse constituir-se professor, a formação inicial tem um papel importante, pois, é o contexto em que a formação se assume como replicação ou como biografia a ser construída.

A formação inicial tem desse modo, o desafio de ajudar os sujeitos iniciantes a fazer a passagem de suas pré-compreensões sobre ser professor para compreensões elaboradas e alargadas sobre a docência e a profissão produzidas pela pluralidade das ciências da educação. Pimenta (2009, p. 20) destaca que os alunos ao chegarem à formação inicial já apresentam uma série de pré-compreensões sobre ser professor.

[...] já têm saberes sobre o que é ser professor. O saberes de suas experiências de alunos que foram de diferentes professores em toda a sua vida escolar. Experiência que lhes possibilita dizer toda a sua vida escolar. Experiência que lhes possibilita dizer quais foram os bons professores, quais eram bons em conteúdos mas não em didática, isto é, não sabiam ensinar. Quais professores foram significativos em suas vidas, isto é, contribuíram para sua formação humana. Também sabem sobre o ser professor por meio da experiência socialmente acumulada, as mudanças históricas da profissão, o exercício profissional em diferentes escolas, a não valorização social e financeira dos professores, a dificuldade de estar diante da turma de crianças e jovens turbulentos, em escolas precárias; sabem um pouco sobre as representações e os estereótipos que a sociedade tem dos professore, através dos meios de comunicação. Outros alunos já tem atividade docente. Alguns, porque fizeram o magistério no ensino médio [...] o desafio então, posto aos cursos de formação inicial é o de colaborar no processo de passagem dos alunos do seu ver o professor como aluno ao seu ver-se como professor. Isto é, de construir a sua identidade de professor. Para o que os saberes da experiência não bastam.

A passagem do "ver o professor como aluno ao seu ver-se como professor" é a tarefa assumida pela formação inicial. Trata-se de tornar claras as pré-compreensões acerca da profissão professor, o que só se torna possível em diálogo com as contribuições compreensivas das ciências da educação. Por isso Pimenta (2009) ressalta a importância de investir na formação inicial, na perspectiva de formar docentes reflexivos, investigadores e identificados com o ser professor. De modo correlato, Facci (2004, p. 57), sugere que a formação inicial reflita "sobre a sua prática" e proponha "aos alunos possibilidades de experimentação, de forma que potencialize suas capacidades de conhecer. O conhecimento do aluno, por meio de suas ações, deve ser o cerne do 


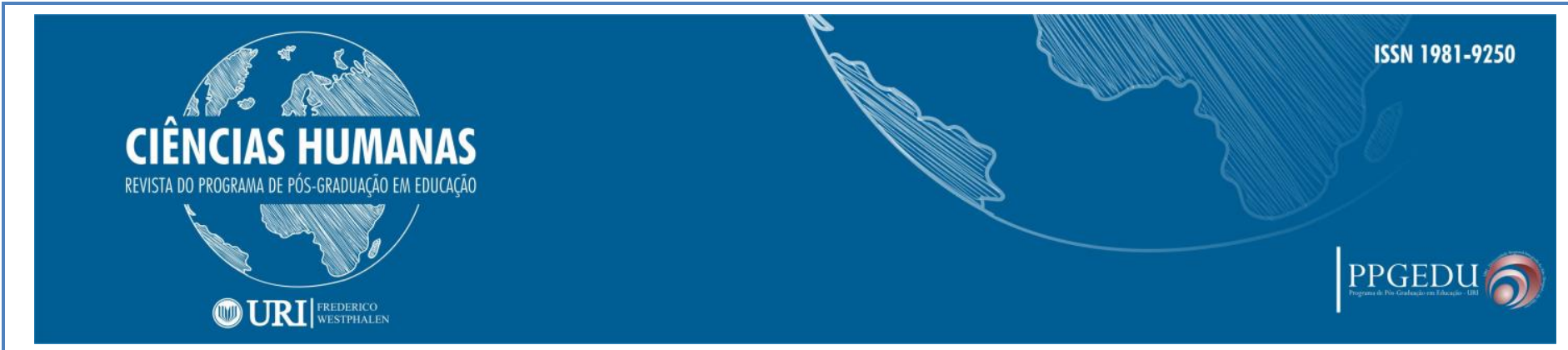

processo educativo". Tal premissa é válida quando se pensa a formação inicial de professores, pois é uma etapa fundamental na vida do futuro docente. É o momento em que se constitui o professor, seu mergulho na tradição, nos conhecimentos e saberes requeridos pela profissão. É nessa construção que se promove a formação de um espírito pesquisador, conscientizando-o que a formação é um caminho permanente.

Espera-se que a formação, inicial e continuada possibilite ao futuro docente a constituição de identidades biografadas. Pimenta (2009, p. 30) destaca a importância "de pensar a formação do professor como um projeto único englobando a inicial e a contínua". Esta afirmação revela que o professor está em constante formação, como destaca Flickinger (2010), um contataste vir a ser, como inacabamento. Também Pimenta (2009, p. 30) reitera a importância de pensar a formação do professor como "reelaboração constante dos saberes que realizam em sua prática, confrontando suas experiências nos contextos escolares; e o de formação nas instituições escolares onde atuam. Por isso, é importante produzir a escola como espaço de trabalho e formação". A formação é o espaço e tempo da construção/reconstrução desses saberes que identificam o professor e o habilitem para a atuação profissional.

Facci (2004) reforça que a formação docente é movimento, é aprofundamento teórico, é resgate e interpretação da tradição, um caminho para significar a prática atual. A tarefa primordial da educação é a construção do conhecimento e a humanização do sujeito e, nesse sentido, "o trabalho do professor consiste em fazer tudo o que for necessário para que o aluno se aproprie do conhecimento" (Idem, p. 17). Diante disso, é importante no processo de formação considerar e valorizar a experiência pessoal dos professores, os conhecimentos sistemáticos e os saberes oriundos da prática. Por outro lado é importante refletir estes saberes da prática a partir de referências teóricos, evitando o risco de reduzir o processo formativo a uma epistemologia da prática.

A este respeito Facci (2004, p. 70) pondera que "somente o conhecimento advindo da prática do professor, produzido no cotidiano da sala de aula, não é suficiente para uma prática que se quer transformadora". Os conhecimentos já produzidos possibilitam contextualizar e, principalmente, atualizar a prática pedagógica. Ressalta ainda que "o conhecimento teórico-crítico, já produzidos pelas gerações anteriores e que 


\section{CIÊNCIAS HUMANAS}

REVISTA DO PROGRAMA DE PÓS-GRADUAĞ̈O EM EDUCAĞ̄o

\section{(1) URI|}

explica a forma histórica de ser dos homens, é que serve de ferramenta para entender e significar a prática atual”. Trata-se de valorizar a tradição à medida que ela nos ajuda a pensar os desafios do nosso tempo.

Neste sentido, o professor é compreendido como mediador de um processo que requer habilidade, estratégias, conhecimento. A esse respeito Libâneo, (2013, p. 37) destaca que: "a tarefa de ensinar a pensar requer dos professores o conhecimento de estratégias de ensino e de desenvolvimento de suas próprias competências do pensar". Apostar nisso significa formar professores que assumam como trajetória ou como biografia a construção de sua identidade profissional. Libâneo $(2013$, p. 86) aponta que "são consideráveis as deficiências do professorado em relação ao aprender a pensar, de modo que eles próprios necessitam dominar estratégias de pensar sobre o próprio pensar". Neste contexto, ressalta-se a importância de o processo de formação desenvolver no docente a capacidade de pensar e refletir sobre sua ação, pois é neste movimento que o sujeito se constrói professor e assume este processo como construção, como biografia.

Destaca-se a importância de considerar a complexidade do processo formativo, especialmente a formação docente. Pimenta $(2009$, p. 10) pondera que "não se pode mais educar, formar, ensinar apenas com o saber (das áreas de conhecimento) e o sabe fazer (técnicoltecnológico). Faz-se necessário a contextualização de todos os atos, seus múltiplos determinantes". Conhecer a tradição teórica e instrumental e fundamental à formação de professores. Nesse movimento o professor compreenderá que seu trabalho pedagógico "necessita de perspectivas filosóficas, históricas, sociológicas, psicológicas etc. perspectivas que constituem o que se pode chamar de cultura profissional da ação, ou seja, que permita aclarar e dar sentido a ação" (Ibidem, p. 10). Assim, pensar a formação de professores como identidades, como biografias, significa interrogar a perspectiva instrumental que tem predominado nas políticas de formação de professores, bem como, nos cursos que assumem uma formação demasiado assentada no fazer pedagógico ou na instrumentalização das futuras professoras (es).

Reconhecer os modelos de formação da Paideia e da Bildung, na perspectiva de retomar compreensões históricas que visavam à formação de sujeitos autônomos, 


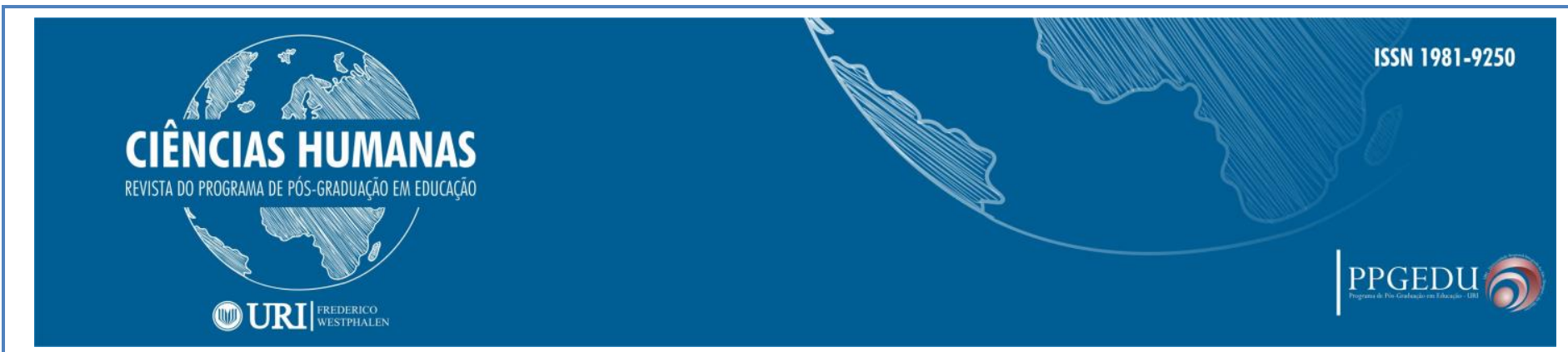

autodeterminados, éticos e capazes de estabelecer relações humanizadoras com o outro e com o mundo, nos permitem interrogar a configuração que a formação professores assume em nosso tempo. Afirmar estes pressupostos da tradição interpela o sentido que temos atribuído à formação humana e dos professores em nosso contexto de capitalismo tardio, em que se propõe uma formação estreitamente vinculada à racionalidade instrumental.

A compreensão da identidade como biografias e/ou trajetórias significa construir um modo de ser, um estilo de vida e docência que fundamentará a trajetória e a ação profissional. O professor identificado com a sua profissão e que a reconhece como biografia e/ou trajetória estará aberto para alargar os horizontes de seus conhecimentos, agir com ética e responsabilidade frente o compromisso social assumido. Pensar a formação humana e docente reafirmando as compreensões da Paideia e da Bildung é interrogar a fragmentação do conhecimento característico da racionalidade instrumental. Esses conceitos ainda são ricos para pensar a formação inicial e continuada dos professores e mobilizam o sujeito na construção de sua identidade.

Esta reflexão ainda é relevante à educação, à formação de professores, à organização da escola se levamos a sério a compreensão de Paideia e Bildung na formação do ser humano. Pensar a formação dos professores para a abertura é fundamental. Portanto, investir na formação de professores identificados com a profissão, comprometidos com a tarefa educativa, com a construção do conhecimento, com uma formação ética e autônoma, nos permite afirmar a importância da profissão no processo humanizador.

\section{REFERÊNCIAS}

ADORNO, Theodor W. HORKHEIMER, Max. Textos escolhidos. São Paulo: Nova Cultural, 1991. p. 132.

APPLE, Michael. A educação e os novos blocos hegemônicos. In: RODRIGUES, Alberto Tosi. Sociologia da educação. 6. ed. Rio de Janeiro: Lamparina, 2011. p. 93122.

CHARLOT, Bernard. A mistificação pedagógica: realidades sociais e processos ideológicos na teoria da educação. São Paulo: Editora Cortez, 2013. p. 412.

\begin{tabular}{c|c|c|c}
\hline Rev. Ciências Humanas & Frederico Westphalen, RS & Pg. 19-37 & Maio/Agosto 2019 \\
\hline \multicolumn{2}{c}{ Recebido em: 09/05/2019 } & Aceito em: 03/06/2019 \\
\hline
\end{tabular}


DARTOD, Pierre; LAVAL, CHRISTIAN. A nova razão do mundo: ensaio sobre a sociedade neoliberal. São Paulo: Boitempo, 2016. p. 413.

DUBAR, Claude. A socialização Construção das identidades sociais e profissionais. Portugal: Porto Editor, 1997. p. 339.

FACCI, Dias Gonçalves Marilda. Formação de Professores Valorização ou esvaziamento do trabalho do professor. Campinas São Paulo: Autores Associados, 2004. p. 302.

FLICKINGER, Hans-Georg. A caminho de uma pedagogia hermenêutica. São Paulo: Autores Associados, 2010. p. 224.

GOERGEN, Pedro. Pós-Modernidade, ética e educação. 2. ed. São Paulo: Autores Associados, 2005. p. 95.

HABERMAS, Jürguen. Teoria de la acción comunicativa. Tomos I. 2. ed. Madrid: Taurus, 2001. p. 470.

HORKHEIMER, Max. Eclipse da Razão. São Paulo: Centauro, 2002. p. 208.

LIBÂNEO, Carlos José. Adeus professor, Adeus professora? Novas exigências educacionais e profissão docente. São Paulo: Cortez, 2011. p. 87.

NÓVOA, Antonio. Vidas de professores. Portugal: Editora Porto, 1995. p. 75.

PIMENTA, Garrido Selma. Saberes Pedagógicos e atividades docentes. São Paulo: Cortez, 2009. p. 246.

SACRISTÁN, J. Gimeno. "Consciência e ação sobre a prática como libertação profissional dos professores". In: NÓVOA, Antonio (org.). Formação de professores. 2. ed. Porto: Portugal, 1995. p. 63-92.

SAVATER, Fernando. El valor de educar. Barcelona: Editorial Ariel, 2008. p. 227.

STEIN, Ernildo. Aspectos filosóficos e sócio-antropológicos do construtivismo pósPiagetiano - II. In: GROSSI, Esther Pillar; BORDIN, Jussara (Orgs.). Construtivismo Pós-Piagetiano. Petrópolis: Vozes, 1993. p. $34-45$.

SUAREZ, Rosana. Nota sobre o conceito de Bildung (formação cultural). In:

Kriterion: Revista de Filosofia, Vol. 46, nº.112, Belo Horizonte, Dez. 2005. p. 191 198. DOI: 10.1590/S0100-512X2005000200005. 